\title{
FACTORES SOCIOESPACIALES \\ DEL DESARROLLO PROGRESIVO EN \\ HÁBITAT POBRES ${ }^{1}$
}

\author{
Patricio de la Puente lafoy ${ }^{2}$, Emilio Torres Rojas ${ }^{2}$ \\ Patricia Muñoz Salazar ${ }^{2}$, Rubén Sepúlveda Ocampo ${ }^{3}$
}

\section{EL PROBLEMA}

El problema habitacional de las familias de menores ingresos ha sido enfocado en el país a través del tiempo desde diversas perspectivas teóricas, políticas y programas.

En atención a la magnitud del déficit de viviendas y a la limitación de los recursos necesarios para afrontarlo se han intentado nuevas modalidades de gestión inspiradas en la idea que en vez de entregar casas terminadas o viviendas definitivas como producto final, a las que muy pocas familias marginales pueden acceder de partida, se conciba el problema habitacional en términos de un proceso social que privilegie una gradual consolidación de las viviendas y el hábitat residencial a través de la entrega de soluciones mínimas susceptibles de ser mejoradas progresivamente por los beneficiarios.

Con este enfoque el problema habitacional se desplaza desde la mera carencia de edificios hacia un tema necesariamente multidimensional y dinámico que requiere ser abordado desde una perspectiva transdisciplinaria que integre variables socioespaciales.

En este contexto, en 1982 se facultó a las Municipalidades para actuar como ejecutores directos o mandantes de programas de infraestructura sanitaria en asentamientos precarios que no contaran con urbanización o la tuvieran parcialmente, incluyendo una caseta con baño, cocina y lavadero conectada a las redes de agua potable, alcantarillado y electricidad, entregándose además a cada familia beneficiaria la propiedad de un terreno con una superficie mínima de $100 \mathrm{~m}^{2}$ con una subvención municipal de hasta $75 \%$ del precio de venta, correspondiendo el saldo a un préstamo hipotecario a doce años plazo, sin intereses, pagaderos en cuotas mensuales.

Este programa de Lotes con Servicios y Mejoramiento de Barrios que se ha llevado a cabo mediante tres préstamos financiados por el BID, que en conjunto han ascendido a 285 millones de dólares, ha pretendido reducir las condiciones de marginalidad sanitaria de las familias de bajos ingresos del país. Esto se logra mediante su radicación definitiva en el mismo territorio que ocupan, o bien, cuando ello no es posible por emplazarse en terrenos de riesgo geofísico o ser propiedad de particulares no susceptibles de adquirir, se recurre excepcionalmente a la erradicación, construyendo nuevos conjuntos de lotes con servicios.

\footnotetext{
${ }^{l}$ Este artículo forma parte del Proyecto fondecyT 1114-92 "La incidencia del Programa de Lote con Servicios en el Desartollo Progresivo. Evaluación y propuesta regionalizada", realizado por el Departamento de Sociología y el Instituto de la Vivienda, ambos de la Universidad de Chile, y el Departamento de Inversiones del Ministerio del Interior.

${ }^{2}$ Sociólogos, académicos del Departamento de Sociología. Facultad de Ciencias Sociales de la Universidad de Chile.

3 Arquitecto, Director del Instituto de la Vivienda. Facultad de Arquitectura y Urbanismo de la Universidad de Chile.
} 
El programa contempla varias posibilidades de acuerdo a la infraestructura existente y a la propiedad de los terrenos, pudiendo variar desde la construcción de casetas y obras deficitarias - como carencia de pavimentación en aceras, falta de muros de contención, de sistemas de evacuación de aguas lluvias, entre otras - hasta obras de urbanización completas en lotes nuevos que incluyen la unidad sanitaria y el título de dominio.

Estas acciones no han estado exentas de controversia. Los defensores del programa centran sus argumentos en su rápida aplicación concordante con la urgencia de los demandantes, el elevado costo de las soluciones habitacionales definitivas, el divorcio entre las necesidades y aspiraciones de los beneficiarios respecto de viviendas consolidadas no posibles de adaptar a los ciclos vitales de las familias.

Los críticos han enfatizado la segregación espacial que conllevan estos programas, el excesivo crecimiento en extensión que ha significado para las ciudades y su falta de adecuación a terrenos que presentan características geomorfológicas distintas.

En los hechos sin embargo, los asentamientos de lotes con servicios han demostrado distintas evoluciones, progresando algunos con rapidez mientras otros se han deteriorado. Así existen ejemplos sorprendentes de evoluciones positivas en este tipo de conjuntos que en forma modesta han ido incorporando diversos servicios de infraestructura, mejorando notablemente la calidad inicial. Ellos contrastan con muchos otros que permanecen en el deterioro y el olvido, manteniéndose vigente la polémica.

Algunos estudios han detectado la importancia que diversas variables socioespaciales tienen en los procesos de mejoramiento habitacional y residencial. Se sabe que tanto las posibilidades económicas como la composición social de los habitantes influyen en su organización y capacidad de gestión, lo cual es decisivo para la evolución positiva del asentamiento (Rosembluth, G., 1979). En el proceso de consolidación de la vivienda influye su condición inicial, calidad de los materiales de construcción, la infraestructura de servicios, aspectos relativos a la proporción y escala de los conjuntos, etc. (Laquián, A., 1985).

Sobre este tema existen interesantes resultados de investigaciones emprendidas en el país, pero que en su mayoría corresponden a estudios monodisciplinarios centrados en la ciudad de Santiago en base a muestras intencionadas, haciéndose sentir una carencia de indagaciones que tratan esta temática desde una perspectiva integradora que incluya tanto la acción del habitante en el incremento de la calidad de la vivienda y su entorno inmediato, como la participación de vecindarios y comunidades en el desarrollo progresivo del hábitat.

En consideración a lo anterior, el objetivo central de este artículo consiste en conocer las relaciones que presentan algunas variables socioespaciales relevantes respecto del proceso de desarrollo progresivo en tres sistemas - familia, vecindario y comunidadal interior de ocho conjuntos residenciales de lotes con servicios emplazados en cuatro regiones del país.

\section{MARCO TEÓRICO INTEGRADO}

Los hábitat residenciales han sido estudiados a través de distintos enfoques que han enfatizado los aspectos socioculturales o fisicoespaciales según sean los intereses propios de las vertientes sociológicas o arquitectónicas.

Aunque esta distinción analítica de la realidad ha proporcionado conocimientos de 
gran valor, también ha conducido a explicaciones reduccionistas producto del desarrollo de marcos conceptuales independientes. De esa forma, se ha intentado dar cuenta de la dinámica social aludiendo a variables fisicoespaciales como causas, o se ha pretendido que los cambios en la base material de los hábitat son siempre función de la cultura y la estructura social.

Durante las tres últimas décadas, los estudios de los fenómenos urbanos han utilizado una perspectiva sistémica para abordar globalmente dicha realidad. Ya desde la década del cincuenta resultaba clara la utilidad de principios sistémicos en el análisis de los fenómenos urbanos, los cuales han transitado desde una concepción mecánica hacia una visión evolutiva (Bailly, 1978).

No obstante, los diversos enfoques continúan vinculados a la línea clásica de la Teoría General de Sistemas que, como tal, puede aplicarse indistintamente a una diversidad de fenómenos desde una perspectiva holística, superando el estudio de partes aisladas. Las contribuciones efectuadas en el ámbito urbano a partir de esta perspectiva se han basado directa o indirectamente en la noción de sistemas abiertos formulada por Ludwig von Bertalanffy hacia mediados del presente siglo.

Con posterioridad, la formulación de una teoría de sistemas socioculturales como una vertiente con principios propios y contenido independiente, aplicable a realidades sociales concretas, ha permitido avanzar fructíferamente en el análisis de diversas temáticas. El principal aporte en este sentido se encuentra representado por la obra del sociólogo alemán Niklas Luhmann, quien rompe con la tradición disciplinaria precedente, sustituyendo las ideas clásicas de causalidad sistémica, descartando la supuesta existencia de constantes estructurales (Arnold, 1988).

Por otra parte la comprensión de los componentes fisicoespaciales en realidades que son producto de la acción humana - como las ciudades - ha llevado a los especialistas a utilizar la noción de "lugar", elaborada por Georg Simmel y que fuera desarrollada más tarde por Joseph Muntañola, David Canter y Christian Norberg-Schultz, entre otros, en orden a conectar las propiedades del espacio con elementos simbólicos y de significación.

En este artículo se elaborará una síntesis de categorías teóricas básicas tanto del enfoque Luhmanniano como de la noción de "lugar", a partir de las cuales se propondrá un esquema integrador como marco conceptual de la investigación.

\section{Principales categorías teóricas del Enfoque Luhmanniano}

Luhmann representa en la actualidad una de las más importantes corrientes de pensamiento en Europa, iniciando una gran polémica al proponer un nuevo modo de pensar la sociedad basado en la teoría general de sistemas, desde la cual reformula radicalmente el pensamiento sociológico contemporáneo (Rodríguez y Arnold, 1991).

Para alcanzar dicho propósito, el autor recurre a la teoría de sistemas para ubicarse en una perspectiva que le otorgue la máxima amplitud en la descripción de realidades que estructuran relaciones a través de la diferencia entre sistema y entorno. Basa su construcción teórica en la realidad de estos fenómenos de diferenciación, con lo cual quiere decir que existen sistemas objeto de investigación que justifican el empleo del concepto de sistema, siendo posible estudiar las funciones de las estructuras sin que sea necesario suponer una totalidad como punto de partida (Luhmann, 1991). Como el sistema ya no se considera como algo "dado", resulta plausible preguntarse por su actividad fundamental que es, según el autor, la comprensión y reducción de la complejidad del mundo circundante (Luhmann, 1973: 113). 
En el núcleo de esta teoría se distinguen tres tipos de sistemas autorreferentes que son los sistemas vivos, los sistemas síquicos $-o$ relativos a las personas como individuos-y los sistemas sociales. Cada uno de ellos se diferencia por la particular forma en que realizan sus operaciones y reducen la complejidad de sus entornos, de manera que los aspectos biológicos son propios de los sistemas vivos, la conciencia es el modo de operación de los sistemas síquicos y la comunicación es el rasgo característico y definitorio de los sistemas sociales (Luhmann, 1991).

Estos grandes sistemas se diferencian de sus propios entornos construyendo formas particulares de comportamiento. Así, al constituirse cada uno de estos sistemas como conjuntos autopoiéticos, es decir, capaces de reproducir los elementos de los cuales se compone, no mantienen contacto directo entre sí. Pese a ello, el autor considera que existe una forma de relación entre estos macrosistemas denominada interpenetración. Mediante esta operación un sistema pone a disposición de otro su propia estructura, para que este último pueda construir su propia complejidad. En este sentido los sistemas sociales suponen vida (Rodríguez y Arnold, 1991). Lo mismo ocurre en el caso de la relación entre persona y sociedad; para que una sociedad pueda existir son necesarias las personas, que a partir de sus estructuras permitan la construcción de otras nuevas, con formas de operación que no se basan en la conciencia individual sino que en la comunicación.

Además, la sociedad es un sistema autorreferente (capaz de referirse a sí mismo tanto en la constitución de sus elementos como en las operaciones que realiza) y autopoiético (capaz de reproducirse a partir de sus propios elementos), que se compone de comunicaciones y que puede, a su vez, diferenciarse en distintos subsistemas, cada uno de ellos cerrado y autorreferente que poseen un ámbito determinado de comunicaciones, delimitando sus propios entornos y reduciendo la complejidad de un modo especializado.

Luhmann plantea que los sistemas sociales no están compuestos por personas sino de comunicaciones generadas a partir de un sentido compartido. Los seres humanos, en consecuencia, no pertenecen al sistema social, sino a su entorno (Rodríguez y Arnold, 1991:113). Ello no significa que un sistema social pueda existir sin seres humanos, sino que los supone como base, sosteniendo que los sistemas psíquicos y los sociales han surgido coevolutivamente como realidades clausuradas en relación a sus propias operaciones de manera que ninguno puede determinar la autopoiesis del otro ni sus cambios de estado, puesto que ello depende de su propia estructura.

Esto implica que todo sistema social presenta fugacidad en tanto desaparece cuando termina la última comunicación que no ha logrado conectarse con otra posterior para mantener su permanencia en el tiempo. El problema básico de todo sistema social es entonces seguir reproduciendo comunicaciones para asegurar su permanencia, ya sean de carácter afectivo en el sistema familiar, teorías en la ciencia, decisiones en las organizaciones, etc.

Sin embargo, la aplicación del enfoque Luhmanniano a la dinámica de los hábitat residenciales no puede efectuarse sin una conceptualización previa del espacio como una dimensión de la realidad susceptible de adquirir sentido para los sistemas sociales. En tanto teoría sociológica, dicha discusión no ha sido desarrollada por este autor ya que trata sobre la configuración de los sistemas sociales en general, sin considerar en particular a aquellos que, como los conjuntos residenciales, incluyen el territorio como una categoría que contribuye a fundamentar el sentido de las comunicaciones que allí ocurren. 


\section{Espacio y Lugar}

Una premisa básica que sustenta este enfoque teórico integrado se refiere a la realidad de los sistemas de comunicación que, por el hecho de ser producto de la práctica social, se sitúan necesariamente en el tiempo y en el espacio.

El espacio constituye un concepto impersonal conformado por relaciones entre formas geométricas. Sin embargo, desde la perspectiva de los sistemas autorreferentes no es posible definir un espacio con independencia de un observador capaz de establecer límites a ese espacio y atribuirle significado a ciertos cuerpos reconocibles en él. Si bien esos cuerpos pueden romper la infinitud de la extensión espacial, las fronteras que establece el observador son relativas. En otras palabras, no existe la delimitación absoluta del espacio válido para todos los observadores, sino que en el caso de los sistemas sociales surge como producto de selecciones compartidas en torno a los elementos escogidos como delimitadores.

Lo anterior puede postularse si se asume que el espacio en sí mismo no constituye un sistema. El espacio no se autolimita sino que siempre es limitado por algún sistemaobservador, sean éstos síquicos o sociales, por tanto no posee sólo una connotación física y natural ya que como realidad concreta requiere ser vivida por alguien, pudiendo conocerse sus atributos mediante la experiencia. La imagen colectiva que se hace de él corresponde a un espacio percibido con el cual cada sociedad se identifica (García, 1986); por ello, aunque el espacio constituye una dimensión del medio ambiente, supera lo puramente físico y tridimensional (Frampton, 1990).

Debido a esta doble realidad física y humana, diversos autores prefieren emplear el concepto de Iugar para representar la relación entre lo espacial y lo social. Lugar es entonces tiempo en el espacio, pues alude a un proceso de lugarización que surge sobre la base de la experiencia y la asignación de sentido (Muntañola, 1973). El espacio y las personas constituyen el ambiente de los sistemas sociales, convirtiéndose en lugar cuando es observado y adquiere significación. Como cada sistema se diferencia generando su propio entorno, aquellos sistemas sociales que utilizan preferentemente pautas interaccionales directas (con cercanía espacial), tienen mayor probabilidad de diferenciar un cierto espacio que identifique el tipo de comunicación que se desarrollará en su interior.

Siguiendo al sociólogo alemán George Simmel, Muntañola señala que la naturaleza social del lugar es posible de ser profundizada si se acude a la definición kantiana del espacio como posibilidad de coexistencia. Surge así un conjunto de rasgos propios del espacio socializado entre los que se encuentran: a) Su exclusividad, es decir, cualquier trozo de espacio es único; b) La existencia de límites por la práctica social, que implica que éste no es un hecho espacial con repercusiones sociológicas, sino un hecho sociológico con forma espacial; c) Que los contenidos de las relaciones sociales se fijan dentro de un espacio determinado (Simmel, 1939).

La expresión simbólica del espacio hace posible la estabilidad de los grupos, facilitando su identificación, sentido de pertenencia y asignación de valor. La permanencia en un sitio favorece la formación de una imagen ambiental que posee identidad, estructura y significación, y que, por tanto, puede ser comunicada al interior de un sistema social (Norberg-Schultz, 1983).

Estos argumentos han conducido a algunos autores a postular que acción y espacio son indivisibles, puesto que la acción se apoya en un tipo de espacio y éste a su vez reafirma una determinada acción, conformando un patrón de acontecimientos que es 
inventado por la cultura (Canter, 1977). En otras palabras, lo social no puede existir fuera del espacio ya que éste, en cuanto sitio significativo, deja de ser una pura forma geométrica para constituir un lugar reconocido y diferenciado por un grupo con el propósito de transformarse en el ámbito específico donde se efectúa determinada comunicación con sentido. De esta forma, los grupos generan lugares donde cierto tipo de comunicaciones son coherentes y válidas, en tanto otras resultan fuera de contexto.

La lugarización se produce como un proceso de diferenciación del territorio que efectúa un sistema previamente constituido, por cuanto el espacio por sí solo no genera sistemas sociales. De este modo el hecho que las comunicaciones se efectúen en un tipo de espacio determinado requiere que éste haya sido construido significativamente por el sistema social de manera previa.

Lo anterior implica que el espacio posee influencia sobre los sistemas sociales y que ésta se encuentra determinada por la definición que con anterioridad un sistema ha efectuado respecto de él. De ahí que un mismo espacio pueda ejercer diversas influencias en distintos sistemas. Como estas influencias no constituyen comunicación propiamente tal pueden asumirse bajo lo que Luhmann denomina irritación, que representa los efectos no traducibles completamente por el sistema y que constituyen exigencias del exterior ante las cuales se debe reaccionar para operar de manera efectiva (Luhmann, 1991).

La expresión simbólica del espacio hace posible la estabilidad para los grupos y en consecuencia el desarrollo de identificación, imagen, sentimientos de pertenencia y asignación de valor. El lugar, a diferencia del espacio, aparece entonces como una realidad que no concierne exclusivamente a las actividades o sólo a los edificios que las alojan, sino a aquellas unidades de experiencia dentro de las cuales las actividades y la forma física están amalgamadas (Canter, 1977). El espacio como lugar adquiere un destino cuando es reconocido, diferenciado y apropiado por un grupo con el propósito de transformarlo en un ámbito específico donde efectuar comunicaciones con un sentido particular.

Por otra parte, las delimitaciones del espacio aumentan la probabilidad de que las comunicaciones del sistema sigan reproduciéndose, pues al limitarse las posibilidades de interacción se garantiza la atención necesaria para la comunicación (Luhmann, 1991). Es por esta razón que al extenderse los significados propios de un grupo hacia otros mayores, normalmente se modifican las fronteras físicas y simbólicas tanto a nivel micro como macro social.

Ahora bien, teniendo en cuenta los elementos conceptuales expuestos de manera resumida, la tesis central del presente enfoque afirma que en los conjuntos residenciales urbanos estos fenómenos de diferenciación socioespacial poseen un correlato en a lo menos tres sistemas reconocibles producto de comunicaciones autorreferentes: la familia, el vecindario y la comunidad. Cada uno de ellos tiende a generar límites que tornan significativas determinadas acciones para cada sistema-lugar.

\section{Propuesta Teórica}

Cabe indicar que los elementos conceptuales que aquí se exponen no deben entenderse como un modelo completo sino más bien como bases provisionales para el desarrollo de un enfoque integrado aplicable al análisis de fenómenos socioespaciales, privilegiándose la interpretación de procesos de diferenciación sistémica que ocurren al interior de hábitat urbanos pobres a fin de lograr una mejor comprensión de procesos de mejoramiento residencial. 
La dinámica de cambio al interior de conjuntos residenciales urbanos pobres puede ser esquemáticamente descrita a través de distintos momentos de evolución. Además implica el desarrollo de tres sistemas básicos de comunicación con sus respectivos límites socioespaciales que permiten identificar y diferenciar el significado que asumen para las agrupaciones humanas las acciones de progresividad y mejoramiento.

En un primer momento el hábitat se expresa en un conglomerado residencial, constituido por un agregado de familias que tienen la potencialidad de articular posteriormente vecindarios o comunidades, aunque al inicio expresan necesidades y aspiraciones organizadas sólo en torno al sentido de la comunicación familiar. La familia —donde la comunicación significativa se vincula emotivamente a lazos de parentesco- define su lugar a partir de la vivienda y el sitio circundante, como el ámbito propio donde la comunicación ocurre. Así, la casa, que es el espacio significativo para la interacción familiar, se transforma en vivienda a partir de un proceso de lugarización, lo que implica generar un referente espacial que permite situar la comunicación. Como sistema, la familia clausura su comunicación en torno a su propio sentido, así como la puerta de la casa se cierra para aislar la vivienda del ambiente externo.

Es necesario reconocer el hecho que en la configuración inicial del sistema de comunicaciones los aspectos espaciales no están involucrados directamente. Esto quiere decir que en el caso de la familia el espacio habitacional disponible la puede afectar, contribuyendo a disgregarla, por ejemplo, cuando el hacinamiento resulta insoportable. Lo anterior implica que las variables espaciales no forman parte sustancial del proceso de diferenciación sistémica que hacen posible un sistema social de comunicación. De hecho los sistemas sociales no surgen motivados por la necesidad de diferenciarse de una cierta extensión de territorio, ni siquiera de cualquier objeto físico existente, sino que surgen de la diferenciación que efectúan de otros grupos mayores con el propósito de generar ámbitos restringidos de sentido que permitan efectuar ciertas operaciones de manera eficaz.

La correlación entre un sentido autorreferencial y un referente fisicoespacial determinado que en forma conjunta dan cuenta del lugar ratifican a la familia como el sistema de mayor estabilidad. El sistema familiar surge habitualmente antes que la vivienda, pudiendo cambiar muchas veces de residencia sin alterar fundamentalmente el sentido de la comunicación familiar, aunque con ello se vean alterados los atributos del lugar por involucrar una nueva dinámica de adaptación al espacio.

Con el tiempo tienden a estructurarse nuevos límites de comunicación con sentido distinto al familiar configurándose el vecindario, que por estar basado en la simpatía mutua incluye sólo algunas de las familias cuyos domicilios se encuentran próximos. De ahí que no todo un pasaje, calle o cuadra, se identifique como el lugar propio de la interacción vecinal, sino sólo aquel espacio donde este tipo de comunicación ocurre con mayor frecuencia. La comunicación con sentido vecinal incluye las conversaciones habituales, favores, encargos y otras pautas de comportamiento basadas en la confianza recíproca.

El sistema vecinal emerge como expresión de simpatía, amistad y solidaridad, siendo sus límites variables entre un conjunto residencial y otro, por lo que no pueden ser definidos previamente, desde fuera. Con los años, el entorno inmediato a las viviendas se convierte en una unidad de experiencia colectiva, en un lugar vecinal. Cuando esto ocurre, los vecinos ejercen un control territorial respecto de él, identificándose como "su lugar". 
No siempre con la permanencia prolongada en un conjunto habitacional emerge el sistema vecinal, pues la proximidad residencial no es condición suficiente para que los vecinos establezcan relaciones sociales armónicas. Cuando existen fuertes tensiones sociales se reducen los sentimientos de identificación, territorialidad, pertenencia y arraigo con espacios que podrían haberse convertido en lugares vecinales. Un ambiente social percibido como hostil y potencialmente agresivo puede provocar en las personas que conforman el vecindario un repliegue hacia el sistema familiar y su espacio privado como el ámbito que ofrece una mayor seguridad para reducir la complejidad del entorno.

Aunque en el vecindario exista una dilimitación compartida del espacio, ello no implica necesariamente que este sistema dirija su atención hacia el espacio intermedio (próximo a las viviendas) para efectuar acciones de mejoramiento. En rigor ellas no forman parte de la comunicación vecinal, puesto que si así fuera se debería esperar un mayor desarrollo de dichos espacios del que efectivamente ocurre.

La interrogante ¿por qué si existen muchos vecindarios no todos hacen arreglos en sus respectivas calles y pasajes? puede ayudar a clarificar esta situación. La respuesta radica en la existencia de otro sistema de comunicación que pone el acento en la realización de acciones de mejoramiento en el espacio público y en la organización. Los sistemas que efectúan arreglos a través de la participación, aunque sean muy pequeños, deben considerarse comunidad y no vecindario, puesto que para la consecución de un logro colectivo es necesario superar la mera amistad y simpatía mutua mediante la socialización de un nuevo contenido, es decir, creando otro sistema de comunicaciones orientado a una función diferente.

La comunidad puede coincidir, ser más reducida o desbordar los límites espaciales y sociales del vecindario. Aunque las mismas personas que conforman con sus comunicaciones los límites del sistema vecinal actúen como comunidad si deciden efectuar mejoras en su calle, por ejemplo, también es posible que el sistema se restrinja cuando sólo algunos vecinos se interesan en la iniciativa, o bien se amplíe, en tanto dicho objetivo intercepta el interés de personas que residen en otros vecindarios cercanos.

Si bien el carácter particularista e íntimo del vecindario representa un poderoso factor que facilita el contacto entre los vecinos para proponer contenidos externos a la comunicación de simpatía típica (como puede ser el arreglo colectivo del entorno), el sistema comunitario no puede sostenerse sólo en ello, requiriendo necesariamente de la racionalidad instrumental para lograr la consecución de sus objetivos. La incorporación de elementos de formalidad, en términos de división de funciones, planificación de tareas o atribución de responsabilidades específicas y por tanto, de control de obligaciones, torna posible la participación en el mejoramiento de diferentes tipos de espacios. Esto se concreta desde el acuerdo entre los vecinos para instalar una simple banqueta en una vereda hasta los grandes esfuerzos colectivos destinados a dotar de costosos equipamientos a un conjunto residencial.

Puede concebirse entonces a la comunidad como un híbrido comunicacional que comparte elementos formales e informales, porque necesita tanto de la integración emotiva propia del grupo primario como de la eficacia organizada de los grupos secundarios. De esta manera la comunidad puede reemplazar la falta de recompensa material para sus miembros a la vez que adaptarse a una contingencia más elevada, que deriva de la incorporación de personas no siempre conocidas y de la necesaria vinculación que debe establecer con sistemas externos (Municipalidad, y otros servicios públicos centralizados ) descentralizados). 
La comunidad constituye una configuración socioespacial que emerge desde dentro en base a criterios territoriales comunes a quienes la conforman. Pensar que la comunidad se identifica necesariamente con la totalidad de un conjunto residencial es erróneo, porque su extensión espacial no determina por sí misma el sentido de las comunicaciones comunitarias. Tampoco es posible identificar ningún elemento objetivo que impulse siempre al sistema comunidad a delimitar todo el espacio que conforma un área residencial, como sucede "desde fuera" con las divisiones territoriales que efectúan los municipios para organizar las demandas de la población mediante unidades vecinales.

Por otra parte debe considerarse que el sistema comunidad se conforma en una etapa avanzada de la evolución de los conjuntos residenciales, pues requiere de una toma de conciencia sobre problemas que afectan a todos los habitantes del conjunto, o al menos a un número significativo de ellos, y que es necesario articular organizaciones eficaces para resolverlos. De este modo las comunidades organizadas, estén reconocidas legalmente o no, poseen como objetivo general promover en su propio espacio un desarrollo sostenido de alguna dimensión socialmente relevante. Surgen de una definición compartida respecto de cierta realidad socioespacial en la que se habita y se convive, trascendiendo el sentido del parentesco y la amistad para incorporar la participación como eje central de un nuevo tipo de comunicación que permite superar problemas con mayor eficiencia que si se opera exclusivamente dentro de los límites de la familia y el vecindario. Entonces es posible encontrar diversas modalidades de acción comunitaria, desde juntas de vecinos con directivas y representantes formales, hasta pequenas organizaciones articuladas por manzanas o calles.

De acuerdo a esta perspectiva teórica, los llamados procesos de desarrollo progresivo no se limitan exclusivamente al mejoramiento de las condiciones materiales de las viviendas, siendo éste sólo uno de sus aspectos. La distinción de tres sistemas-lugar con rasgos autorreferenciales y autopoiéticos que establecen límites socioespaciales, permite entender que la progresividad también ocurre en el sistema comunidad porque incorpora dimensiones igualmente centrales para definir las condiciones de habitabilidad.

\section{METODOLOGÍA}

Los resultados que se presentan proceden de un survey social realizado durante los meses de junio y julio de 1993 a través de una encuesta estructurada que se administró a 485 beneficiarios del Programa de Mejoramiento de Barrios del Ministerio del Interior, en el período 1982-1992.

Sobre la base de los antecedentes emanados del Banco de Proyectos de este programa proporcionados por el Departamento de Inversiones del Ministerio, se confeccionó un listado de las 135.223 unidades sanitarias entregadas en el lapso de estudio ya fueran radicaciones o erradicaciones. A partir de esta información se seleccionó una muestra a nivel nacional, de acuerdo a dos criterios básicos: el número de soluciones implementadas y la representatividad de una sectorización habitacional del país, recurriendo para ello a la realizada por los arquitectos O. Sepúlveda y G. Carrasco (1991). En función a los criterios antes mencionados se eligieron las regiones III, Metropolitana, VIII y X.

A continuación se consideraron las comunas que concentraban un mayor número de soluciones, siendo seleccionadas Copiapó, Conchalí, Recoleta, Concepción, Talcahuano, Osorno y Puerto Montt. El tamaño muestral fue de 485 casos para obtener un margen de 
REVISTA DE SOCIOLOGÍA

error de $4 \%$ que se distribuyeron en ocho conjuntos habitacionales, tal como se indica en el siguiente cuadro:

\section{CARACTERÍSTICAS DE LOS CONJUNTOS SELECCIONADOS}

\begin{tabular}{lcccc}
\hline REGIONES Y & Tamaño & Antigüedad & Año intervención & $\mathrm{N}^{\circ}$ \\
COMUNAS & Población & Población & Caseta Sanitaria & de casos
\end{tabular}

TERCERA:

Copiapó:

Pedro León Gallo

1459

1952

1986

62

(Radicación)

Juan Pablo II

369

1991

1991

60

(Erradicación)

\section{METROPOLITANA}

Conchalí:

Santa Mónica

536

1964

1983

66

(Radicación)

Recoleta:

Santa Ana

434

1970

1991

61

(Radicación)

\section{OCTAVA:}

Talcahuano:

Santa Julia

54

1991

1991

(Erradicación)

Concepción:

Santa Sabina

970

1968

1985

(Radicación)

\section{DÉCIMA:}

\section{Osorno:}

Carlos Condell

1211

1972

1986

67

(Radicación)

Puerto Montt:

B. O'Higgins

(Radicación)

La estimación del total de las unidades muestrales, se efectuó a través de la fórmula para poblaciones infinitas (universo mayor de 100.000 casos), por ajustarse a los requerimientos de la investigación.

Para determinar las agrupaciones residenciales específicas a seleccionar al interior de cada comuna, por constituir una categoría central en el estudio de la progresividad, se empleó un criterio temporal, distinguiéndose conjuntos recientes (con menos de 3 años) y antiguo (más de 5 años), procediéndose a elegir un conjunto de cada tipo. 
La selección de los lotes con servicios al interior de cada agrupación residencial, se efectuó sobre la base de información planimétrica, siguiendo procedimientos aleatorios sistemáticos, asegurando que todos los casos tuvieran la misma probabilidad de ser incluidos en la muestra y se distribuyeran homogéneamente en toda la superficie de ella.

Finalmente, en cada lote se procedió a encuestar a la dueña de casa en consideración a que ella es generalmente la persona que puede proporcionar información más confiable respecto a los temas que se investigaron. El trabajo en terreno se efectuó durante los meses de junio y julio de 1993, desempeñándose como encuestadores personal técnico-profesional de los Departamentos de Desarrollo Comunitario de las Municipalidades, los que fueron especialmente entrenados y supervisados en terreno por los investigadores del proyecto.

Cabe consignar que el cuestionario había sido sometido a una prueba piloto realizada en octubre de 1992, en dos conjuntos de la ciudad de Santiago donde se eligió aleatoriamente 15 casos en cada uno de ellos.

El procesamiento de la información se efectuó computacionalmente por medio de la aplicación del programa estadístico S.P.S.S., calculándose las asociaciones mediante el coeficiente $r$ de Pearson. Las correlaciones analizadas en los resultados se presentan con un asterisco $(*)$ cuando es significativa a nivel de 0,05 y con dos $(* *)$ si lo son al 0,01 .

Las variables sociales y fisicoespaciales más complejas fueron sintetizadas a través de índices aditivos simples, en base a un conjunto significativo de dimensiones relevantes. Los índices elaborados con sus correspondientes coeficientes de confiabilidad (Alpha de Cronbach) fueron: de intervención en la caseta (.80); de evaluación de la unidad sanitaria (.80); de arreglos en el sitio antes y después de instalada la caseta (.91 y .77); de progresividad en el sitio (.77); de participación en arreglos de la casa (.72); de sociabilidad vecinal (.78); de organizaciones comunitarias (.51); de infraestructura física (.53); de problemas sociales (.76); de problemas físicos (.46) y de participación comunitaria (.93).

\section{RESULTADOS DEL ESTUDIO}

En esta sección se presentan los principales resultados derivados del análisis asociativo efectuado entre las diversas dimensiones del desarrollo progresivo y un conjunto de variables sociales y fisicoespaciales en los tres sistemas diferenciados al interior de los conjuntos residenciales estudiados. De este modo las influencias detectadas mediante valores de correlación significativos, se presentan ordenadas en cada sistema por grupos de variables como: características básicas de las entrevistadas, rasgos relativos a la situación familiar, dimensiones propias del vecindario y la comunidad además de variables fisicoespaciales del conjunto residencial.

\section{SISTEMA FAMILIA VIVIENDA}

\section{Influencia de las Características Básicas de la entrevistada}

El tiempo de residencia de la entrevista resultó asociado positivamente con el índice de evalución de la caseta $\left(.15^{* *}\right)$, es decir a medida que transcurre el tiempo de caseta es mejor considerada. Esto significa que cuando los habitantes residen más tiempo en un 


\section{REVISTA DE SOCIOLOGÍA}

conjunto, como sucede en las poblaciones de radicación, el beneficio otorgado por el programa representa una solución total a un problema de saneamiento, por lo general largamente esperado. De este modo, su logro tiende a ser comparativamente más valorado que en las situaciones donde la caseta constituye una etapa fundante de una nueva vivienda, como ocurre en los más recientes asentamientos de erradicación incluidos en la muestra.

En cambio esta misma variable se encontró negativamente asociada con el número de intervenciones en la caseta $\left(-.21^{* *}\right)$, lo que pone de manifiesto que los mejoramientos de la unidad sanitaria se generan primordialmente en los primeros años de su instalación como producto de rápidos procesos adaptativos del sistema familiar, de manera que el paso del tiempo no induce a las familias a introducirle nuevos cambios, tendiendo a considerarse como una solución consolidada o terminal.

También se verificó que con el tiempo de residencia se tiende con más frecuencia a considerar que las piezas de la casa son definitivas $\left(.19^{* *}\right)$ y a disminuir el grado de desarrollo progresivo en ésta (-.28**). Ello indica que con el transcurso de los años, el desarrollo progresivo de la vivienda tiende a estancarse, produciéndose la mayor progresividad durante los primeros años como producto de las necesidades de adaptación de la familia en el nuevo contexto habitacional y a sucesivos procesos de lugarización. El mayor desarrollo progresivo experimentado por la vivienda en una etapa inicial es sin embargo precario, siendo probable que al disponer de menos recursos las familias efectúen construcciones provisorias y a considerarlas como tales y que posteriormente, debido a que la consolidación de la vivienda implica mayores costos, la progresividad se produce a una tasa mucho menor.

Además, el tiempo de residencia en la población influye negativamente en la progresividad del sitio $(-.28 * *)$ y en los mejoramientos introducidos con posterioridad a la llegada de la unidad sanitaria $(-.14 *)$. Como se mencionó anteriormente los mayores niveles de progresividad ocurren durante los primeros años de residencia de la familia en el conjunto. Estos hallazgos pueden interpretarse como derivados de una imperiosa necesidad del sistema familiar por lugarizar lo más prontamente posible no sólo su casa, sino también el sitio circundante a ella, contando con un mínimo de seguridad y privacidad.

Por otra parte se pudo comprobar que al aumentar el tiempo de residencia de los habitantes en el conjunto se produce un menor involucramiento de la familia en los mejoramientos introducidos en el sitio y la vivienda $\left(-.15^{*}\right)$, lo que significa que durante los primeros años la mayoría de los arreglos son efectuados por los miembros de la propia familia, en etapas intermedias se realizan con la ayuda de maestros, en tanto que en las avanzadas, la progresividad tiende a ocurrir mediante la contratación de maestros.

La edad de la entrevistada resultó asociada positivamente $\left(.14^{*}\right)$ con la opinión favorable respecto del impacto de la caseta en la situación familiar. Este hallazgo no resulta sorprendente si se tiene en cuenta que la edad de la entrevistada se encuentra fuertemente asociada con el tiempo de residencia en el conjunto $(.50 * *)$, siendo posible sostener que las de más edad corresponden de preferencia a residentes antiguas en conjuntos de radicación. Como en éstos las casetas son relativamente mejor evaluadas, era esperable constatar mayor frecuencia de opiniones favorables sobre las ventajas que ha reportado para el grupo familiar haber sido beneficiaria del programa.

Esta variable también está relacionada con la opinión sobre el grado de consolidación de las piezas de la vivienda, por cuanto a mayor edad se tiende con mayor frecuencia a 
considerarlas como definitivas $\left(.28^{* *}\right)$. Al mismo tiempo también se verificó que con el aumento de la edad, disminuye el desarrollo progresivo de la vivienda $(-.21 * *)$, implicando que su progresividad es mayor cuando las personas son más jóvenes, lo que desde el punto de vista del ciclo familiar corresponde a una etapa de expansión que después tiende a estabilizarse.

La educación es otro factor básico que resulta importante, ya que las personas con más años de escolaridad son las que tienen menor residencia en el conjunto $\left(-.32^{* *}\right)$, son más jóvenes $\left(-.50^{* *}\right)$ y sus viviendas muestran un mayor desarrollo progresivo $\left(.16^{*}\right)$. Esto se vincula con el aumento de la cobertura del sistema educativo formal en las últimas décadas y con el efecto modernizador que ejerce la educación al aumentar la calidad de vida. Así, la educación estaría desarrollando también mayores expectativas habitacionales, impulsando con ella la progresividad en la vivienda.

También la escolaridad muestra relación, aunque moderada, con los niveles de desarrollo progresivo del sitio $\left(.15^{*}\right)$. de manera que allí donde las encuestadas cuentan con más años de educación formal se realizan más arreglos en ellos.

\section{Influencias de la Situación Familiar}

En relación a esta dimensión se pudo comprobar en primer término que cuando el jefe de familia no era el marido de la entrevistada, sino ella misma, un hijo u otra persona - situaciones que revelan un funcionamiento irregular del sistema familiar - la valoración de los elementos, atributos y recintos de la caseta es menor (-.17*). Esto implica que cuando la familia es completa, asumiendo el esposo la jefatura del hogar, tiende a producirse un mayor reconocimiento derivado probablemente de una transferencia de comunicaciones con sentido, propios del sistema familiar hacia el objeto evaluado, aumentando o disminuyendo su significado según esté presente o no el cónyuge.

La jefatura del hogar muestra también una correlación positiva con respecto a las personas que realizan la mayoría de las construcciones y arreglos (.14*). De modo que los arreglos son efectuados en mayor medida por miembros de la familia si el jefe es el marido de la entrevistada, en cambio, existe un menor involucramiento en ellos si la jefatura del hogar recae en otro miembro de la familia, recurriéndose en estos casos a maestros para la mayoría de los arreglos. Esta relación indica que el hecho de usar o no maestros no sólo tiene un componente temporal y económico sino que también se vincula con la estabilidad de la familia.

El aumento del número de personas en el sitio actúa disfuncionalmente, puesto que disminuye el desarrollo progresivo de la casa $(-.14 *)$ al incrementar los problemas por allegamiento, que necesariamente están implicando mayores gastos y menores posibilidades de inversión destinada a la vivienda.

Además un mayor número de personas en el sitio y de personas que usan la caseta, también aumenta la participación en arreglos (.19** y $20^{* *}$ respectivamente). Es probable que al residir más personas en el sitio, exista mayor disponibilidad para que ellas se incorporen como mano de obra en los mejoramientos. Sin embargo, no es posible saber, en base a este resultado, en qué arreglos se tiende a participar y bajo qué condiciones. Esta interrogante puede ser respondida por la asociación entre el número de casas existentes en el sitio y su desarrollo progresivo (.16*). Esto indica que con el aumento de viviendas por sitio también se registra un mayor desarrollo progresivo en él. Resulta importante indicar que esta correlación no se verifica para el desarrollo progresivo de la 
vivienda, lo que puede estar señalando que los allegados externos, representados por la presencia de más de una vivienda en cada lote asignado, se están involucrando preferentemente en los arreglos que se efectúan al sitio y no en los introducidos en la casa principal beneficiaria de la caseta sanitaria.

\section{Influencias del Involucramiento de la Familia en los Arreglos}

En cuanto al grado de involucramiento del sistema familiar en las decisiones para introducir mejoras en la casa o el sitio se pudo advertir que éste se encuentra asociado tanto con la opinión positiva sobre la influencia del programa en la situación familiar $\left(.26^{* *}\right)$ como respecto al número de intervenciones introducidas a la caseta $\left(.17^{* *}\right)$.

Esto puede ser interpretado en términos que un clima social armónico, expresado en la participación de todos los componentes del sistema familiar en las decisiones relativas al mejoramiento del espacio privado, esto es, la vivienda y el terreno, tiende a desencadenar procesos de lugarización manifestados también en numerosas intervenciones tendientes a mejorar la condición inicial de la unidad sanitaria, lo cual redundaría a su vez en un mayor reconocimiento de la influencia positiva de ésta en el mejoramiento de la calidad de vida del grupo beneficiario.

Por otra parte cuando la mayoría de las construcciones o arreglos son realizadas por miembros del grupo familiar, se tiende con más frecuencia a considerar las piezas de la casa como provisorias; en tanto que cuando se construye sólo en base a la contratación de maestros, se las califica como definitivas (-.17*). Esto muestra otros rasgos que asume el desarrollo progresivo en el programa de lotes con servicios. En una primera etapa este desarrollo se produce a una tasa muy alta, pero de calidad precaria dado que la familia no es experta en construcción lo cual lleva a hacer construcciones y a considerarlas como provisorias. Pero a medida que la familia se estabiliza y es capaz de generar mayores recursos, efectúa arreglos mayores que requieren de calificación y por ende, de contratación de maestros que les confiera un carácter más definitivo a los recintos de la vivienda.

Además se pudo constatar que cuando los arreglos son decididos por toda la familia, se produce un mayor nivel de desarrollo progresivo $(.21 * *)$ y construcción de más piezas después de instalada la caseta $\left(.20^{* *}\right)$ que cuando ellos son decididos sólo por la dueña de casa o su pareja.

Asimismo se observó relación entre la evaluación sobre el impacto de la instalación de la caseta en el sitio sobre la situación familiar, la evaluación de la casa y la opinión sobre el grado de consolidación de las piezas. Así, quienes evalúan que la instalación de la caseta en el sitio mejoró la situación familiar, tienden a evaluar mejor la casa $\left(.17^{*}\right)$ y a considerar las piezas como definitivas $\left(.15^{*}\right)$. Esto indica que a medida que se va consolidando la vivienda, se genera una mayor valorización de los arreglos, especialmente en los conjuntos que tienen mayor tiempo, como es el caso de las radicaciones, donde la caseta viene a consolidar una situación habitacional que ya tenía un alto grado de desarrollo de acuerdo al número de piezas consideradas definitivas.

\section{Influencias del vecindario y la comunidad sobre el sistema familiar}

Las peculiaridades de las relaciones de vecindad, derivadas de la convivencia cotidiana entre vecinos, incide asimismo en la valoración tanto de la caseta $\left(.19^{* *}\right)$ como de los componentes y atributos de este recinto $(.19 * *)$. En efecto, cuando los habitantes de los conjuntos opinan que sus vecinos son amistosos, confiables, se ayudan en casos de 
necesidad, no siendo copuchentos ni intrusos —dimensiones que fueron incluidas en el Índice de Sociabilidad Vecinal - tienden a otorgar una mejor valoración a la unidad sanitaria como un todo y a los diversos elementos que la componen. En este caso, de acuerdo al enfoque teórico que inspira esta investigación, podría postularse que se está en presencia de una resonancia experimentada por el sistema familiar derivada de estímulos provenientes de su entorno vecinal, de manera que cuando la percepción de su clima es negativo, siendo la sociabilidad entre los vecinos baja o nula, las familias tienden a conceder evaluaciones insatisfactorias tanto a las casetas consideradas como una unidad, como a sus componentes y atributos. En este mismo sentido se pudo apreciar que a mejor evaluación de la sociabilidad vecinal, aumenta la evaluación de la casa $\left(.20^{* *}\right)$ y se consideran sus piezas como definitivas $\left(.14^{*}\right)$.

El Índice de Evaluación de la Caseta se encontró asociado con el Índice sobre Problemas Sociales prevalecientes en el conjunto residencial, en el sentido que las personas que percibían alta prevalencia de alcoholismo, drogadicción, robos y asaltos, etc., tendían a evaluar negativamente los atributos, componentes y espacios de la unidad sanitaria $(-.17 *)$.

En este caso también es posible interpretar este hallazgo en función de una resonancia en el sistema familiar producida por el clima social imperante en su entorno. Si la convivencia entre los residentes de un conjunto es severamente entorpecida por la percepción de un clima social hostil y potencialmente agresivo o peligroso influye en la evaluación negativa, reveladora de insatisfacción con la solución entregada.

La percepción sobre la existencia de organizaciones comunitarias en el conjunto está asociada tanto a la evaluación de la caseta y de la casa como al índice respectivo. De esta forma aquellos que señalan que en sus asentamientos existen muchas asociaciones voluntarias otorgan valoraciones inferiores comparado a los que señalan que estas organizaciones no existen $(-.16 *$ respecto de la evaluación de la caseta, $-.19 * *$ respecto de la evaluación de la casa y $-.19 * *$ con relación al índice).

La valoración inferior de la unidad sanitaria por parte de quienes residen en conjuntos que cuentan, a juicio de los entrevistados, con un mayor número de asociaciones voluntarias en el sector, podría eventualmente derivar de una mayor exigencia en los estándares de habitabilidad. El hecho que en el hábitat se disponga de varias instancias de participación y que ello sea percibido por sus moradores puede implicar un mayor grado de apertura en el sistema familiar, una mayor capacidad de discernimiento y selectividad del entorno que permitiría disponer de criterios de comparación y aspiraciones más refinadas y elevadas, respecto de quienes viven en contextos que no cuentan con organizaciones sociales en que los habitantes participen o puedan eventualmente participar.

\section{Características Fisicoespaciales}

En cuanto a las características fisicoespaciales del conjunto se verifica que cuando los habitantes perciben un mayor número de problemas físicos en éste, se tiende a realizar evaluaciones más negativas de las casetas $\left(-.19^{* *}\right)$ asimismo cuando los habitantes perciben una infraestructura de equipamiento físico deficitario o de baja calidad los residentes tienden a evaluar la caseta en forma más negativa $(.19 * *)$.

En los conjuntos más jerarquizados y ordenados en cuanto a su trama, vialidad y equipamiento se verifica un mayor reconocimiento respecto a que la instalación de la 
caseta influyó en la construcción de nuevas piezas $\left(.19^{* *}\right)$, con mayor frecuencia se las considera provisorias $\left(-.20^{* *}\right)$, se produce un mayor desarrollo progresivo tanto en la vivienda $\left(.21^{* *}\right)$ como en el sitio $\left(.19^{* *}\right)$ y un mayor número de arreglos efectuados después de instalada la caseta $(.22 * *)$.

Respecto de la topografía del terreno donde se emplazan los conjuntos se puede apreciar que cuando hay pendiente existen menos intervenciones en la caseta $\left(-.15^{*}\right)$ aunque la evaluación de sus distintos componentes es positiva $\left(.23^{* *}\right)$, opinándose además que la instalación de la unidad sanitaria no influyó mayormente en la situación familiar $\left(-.14^{*}\right)$.

Cuando el terreno es plano se construyen más piezas $\left(.26^{* *}\right)$ opinándose que lo más urgente es efectuar grandes arreglos a la casa $\left(.16^{*}\right)$. Estos resultados indican que la caseta en estos casos da respuesta a una necesidad cuya solución es de alto costo para la familia, a pesar de lo cual no pueden iniciar fácilmente nuevos arreglos en la vivienda si su situación socioeconómica no mejora.

\section{SISTEMA VECINDARIO}

\section{Influencias de las Características Básicas de la entrevistada}

El tiempo de residencia en la población de la entrevistada y su edad están negativamente asociados con el lugar donde conversa con los vecinos y el hecho de celebrar con ellos en su calle o pasaje fiestas y conmemoraciones, encontrándose que las residentes más antiguas y de mayor edad no conversan con sus vecinas o lo hacen sólo cuando van de compras, en tanto las más recientes y jóvenes conversan más frecuentemente con ellas de una reja a otra o en el interior de sus viviendas $(-14 * y-18 * *$ respectivamente).

Como dicho entorno a su vez, con el transcurso del tiempo de residencia de las familias en los conjuntos, tiende a ser percibido como hostil y potencialmente peligroso, caracterizado por la prevalencia de problemas sociales tienden a limitar sus interacciones con los vecinos sólo a los contactos inevitables y formales, breves diálogos con motivo de coincidir en los lugares de compra o en su trayecto hacia ellos, cerrándose las comunicaciones a aquellas referidas al sistema familiar mismo y a su espacio privado, representado por su sitio y su vivienda, con lo cual no tendría sentido participar con el recindario en actividades conjuntas en espacios intermedios percibidos y significados como hostiles.

El nivel de escolaridad está en cambio positivamente asociado con el uso de calles o pasajes con ocasión de festividades $\left(.16^{*}\right)$. Un aspecto que ayuda a comprender esta relación es el hecho que la mayor parte de dichas celebraciones constituían cumpleaños de los hijos de las entrevistadas, siendo necesario ocupar el espacio inmediatamente cercano a la vivienda por las pequeñas dimensiones de la mayoría de ellas. En este caso, la educación parece traducir una mayor preocupación por los hijos más que una apropiación del espacio intermedio, pues otras celebraciones colectivas como fiestas patrias o navidades eran muy poco frecuentes entre los vecinos.

\section{Situación familiar}

El número de personas que viven en el sitio se encuentra asociado con la participación de los vecinos en arreglos efectuados en la calle o pasaje $(.14 *)$, lo que significa que cuando 
los terrenos están más densamente ocupados aumentan los mejoramientos en los espacios intermedios con la participación de todos los vecinos del sector. Este resultado indica que cuando hay gran presión en el espacio privado, lo que ocurre especialmente cuando existen allegados, se producen más acciones tendientes a mejorar calles y pasajes junto con otras personas que conforman el vecindario.

\section{Influencia del clima social}

El índice de participación comunitaria está asociado tanto con la cercanía de la vivienda de la entrevistada de las personas con las que se lleva mejor en el barrio $\left(.17^{*}\right)$ como también con el respecto del índice de sociabilidad vecinal $\left(.25^{*}\right)$. Esto es, quienes más participan en organizaciones voluntarias territoriales tienden a convivir mejor y tener amistad con las vecinas que residen en su misma calle o pasaje.

Se puede decir que estos factores tienden a reforzarse mutuamente en términos que cuando los habitantes no participan en organizaciones tienden también a tener una baja sociabilidad con sus vecinas otorgándoles atributos negativos, evitando conversar con ellas.

Además la existencia de organizaciones en el asentamiento se asocia con el grado de participación de los vecinos en arreglos efectuados en las calles o pasajes (.14*), de manera que en aquellos conjuntos en que se perciben diferentes instancias de participación social, aunque los residentes no participen efectivamente en ellos, parece existir un clima social propio del sistema comunitario que los impulsa a realizar arreglos en los espacios intermedios con la intervención activa de todos los vecinos.

En este mismo sentido opera la participación efectiva en juntas vecinales. Allí donde existe mayor participación en estas asociaciones se producen arreglos en las calles o pasajes con la participación de todos los vecinos $\left(.29^{* *}\right)$, siendo el motivo expresado para efectuar los arreglos, precisamente, la amistad existente entre los vecinos $(.24 * *)$.

Otra variable considerada en esta investigación refuerza las interpretaciones anteriores. En efecto, si los residentes de un sector están organizados de manera más inclusiva, incorporando en los arreglos de las calles y pasajes a todos los habitantes de un conjunto en vez de articularlos por cuadras o manzanas, se registra una alta asociación con el uso efectivo de los espacios intermedios y con la cercanía de los contactos o conversaciones con los vecinos $(.25 * *)$. Igualmente cuando existe esta forma de organización de los vecinos el motivo preferente de los arreglos de las calles o pasajes está constituido por la amistad existente entre ellos, participando toda la comunidad residencial en los mejoramientos en vez de algunos vecinos $(.29 * *)$.

Los resultados anteriores permiten plantear que la existencia de un sistema comuni$\mathrm{dad}$, representado por una forma organizativa en la que participan todos los habitantes de un asentamiento tiene más eficacia para el mejoramiento de espacios intermedios que organizaciones menos inclusivas en que sólo participan quienes viven en la misma calle o pasaje donde se efectúan las intervenciones. La amistad entre los vecinos parece representar la base para una delimitación compartida del espacio intermedio tendiente a la lugarización, pero es el sistema comunitario en definitiva quien opera concretando la progresividad en las calles o pasajes de los conjuntos. 


\section{Influencias de las Características Fisicoespaciales de los Conjuntos}

La dotación y calidad de la infraestructura física disponible en los conjuntos habitacionales, representado por el Índice respectivo, se encuentra asociado con el índice de sociabilidad vecinal $\left(.17^{*}\right)$.

Este hallazgo implica que los asentamientos que disponen de más cantidad y mejor calidad de infraestructura, valorado por sus residentes, contribuye a formar un clima de armonía en el vecindario, expresado por opiniones favorables respecto a los vecinos, comprobándose que la ausencia, poca cantidad y mala calidad de los componentes físicos del espacio público residencial, constituyen no sólo un factor de insatisfacción con dichos espacios, sino que repercute negativamente en la posibilidad que los vecinos establezcan comunicaciones socioemocionales significativas, conformadores de vecindario y de comunidad.

El tiempo del asentamiento influye negativamente en el uso de los espacios intermedios por parte de los vecinos $\left(-.20^{* *}\right)$ y en especial para la realización de fiestas en la calle $(.32 * *)$, lo que implica que son los residentes de los conjuntos recientemente construidos quienes más utilizan las calles y pasajes para realizar celebraciones colectivamente. Este resultado en sí mismo puede considerarse sorprendente por cuanto era plausible hipotetizar que con el paso de los años tenderían a producirse contactos más íntimos entre los vecinos que eventualmente los conduzcan a procesos de lugarización de la calle o pasaje. Sin embargo, para interpretar esta asociación habría que recordar que con el transcurso del tiempo cambia el ciclo vital de las familias; así en las poblaciones más antiguas predominan las personas con más edad, cuyos hijos probablemente se han casado y cambiado de residencia.

Las características topográficas del terreno de los asentamientos aparecen asociadas con tres variables: la cercanía del lugar donde viven los vecinos con los cuales conversa la entrevistada $\left(.19^{* *}\right)$, la sociabilidad vecinal $\left(.24^{* *}\right)$ y el hecho de usar calles y pasajes para celebrar fiestas durante los últimos dos años $\left(.25^{* *}\right)$.

El sentido de la asociación indica que cuando la topografía del terreno del asentamiento presenta pendientes pronunciadas, los vecinos conversan más y de manera más próxima entre sí ya que lo hacen con mayor frecuencia y al interior de sus casas o de una reja a otra, manifiestan una opinión más favorable del vecindario y el espacio intermedio cobra un especial significado social, siendo utilizado con motivo de conmemoraciones.

Al parecer, el dominio visual que tienen los habitantes de conjuntos ubicados en laderas de cerros sobre su entorno físico, que incluye hasta los espacios semiprivados de sus vecinos, favorece el surgimiento de territorialidad y de un sentido más colectivo de convivencia y son proclives a gatillar procesos de lugarización de las calles y pasajes, las cuales por la configuración morfológica del terreno resultan más susceptibles de apropiación. En tanto los conjuntos planos tienden a una uniformidad perceptual, a perspectivas limitadas, presentan mayor dificultad de ser significados como una unidad, tendiendo a atomizar las comunidades residenciales.

Por otra parte, la jerarquización de vías del conjunto se encuentra asociada con el uso de espacios intermedios $\left(.21^{* *}\right)$ y especialmente por el hecho de efectuar celebraciones en ellos $(.32 * *)$, de manera que una trama claramente jerarquizada favorece la utilización de estos entornos por parte de los residentes.

Por último el tamaño del conjunto está asociado con el uso de los espacios intermedios $\left(.28^{* *}\right)$, las celebraciones de fiestas en dichos espacios $\left(.29^{* *}\right)$ y con la participación 
más limitada de los vecinos en los arreglos $\left(-.16^{*}\right)$. Esta última asociación revela que cuando los conjuntos habitacionales tienen mayor número de habitantes se tiende a potenciar la participación por cuadras o manzanas, en tanto que en los menos numerosos la progresividad de los espacios intermedios ocurre mediante mecanismos que incluyen a toda la población residencial.

\section{SISTEMA COMUNIDAD}

\section{Influencias de las Características Básicas de la entrevistada}

Uno de los aspectos que caracteriza la situación de la muestra fue el tiempo de residencia de los encuestados en la población, la cual demostró estar asociada positivamente con el índice de problemas sociales $\left(.24^{* *}\right)$ y con el Índice de Organizaciones Comunitarias $\left(.18^{* *}\right)$. La correlación indica que al aumentar los años de permanencia en ella se perciben más problemas sociales y se reconoce un mayor número de organizaciones comunitarias.

Por otra parte, el tiempo de residencia y la edad de la encuestada se encuentran vinculadas en forma directa con la opinión respecto a la intención de quedarse a vivir o mudarse de la población (.16* y $.20 * *)$, respectivamente, indicando que en la medida que ambos factores temporales aumentan se produce una tendencia a un mayor arraigo.

En cambio el nivel de instrucción estuvo correlacionado con la intención de permanecer en la población $\left(-.19^{* *}\right)$. Al parecer las personas con mayor educación asumen estándares más exigentes de habitabilidad, de manera que poseen también mayores expectativas de cambio de residencia que aquellos menos educados, quienes se encuentran probablemente más satisfechos con las características del sector residencial.

\section{Influencia de la situación familiar}

El número de personas que habitan en el sitio se encuentra inversamente asociado al índice de infraestructura física del conjunto residencial (-.12*). Este resultado podría dar cuenta de niveles más elevados de tensión y conflicto al interior de la familia, repercutiendo en una visión negativa hacia la infraestructura. Debe considerarse, sin embargo, que en esta relación también existe una influencia del tiempo en la medida que el número de personas en el sitio tiende a aumentar con los años, de manera que al aumento de la tensión por efecto de la concentración de personas en el sitio, se está sumando el incremento de la conciencia crítica propia de la población con mayor antigüedad en los asentamientos.

La misma interpretación anterior puede aplicarse a la correlación entre el número de casas por sitio y el índice de problemas sociales $\left(.13^{*}\right)$. En este caso también un aumento en el número de viviendas en el sitio coincide con una percepción más pronunciada de problemas sociales en el sector.

Además, tanto el número de personas como la cantidad de viviendas por sitio, correlacionaron positivamente con el índice de organizaciones comunitarias percibidas $\left(.13^{*}\right)$ y $\left(.17^{*}\right)$ respectivamente. Estos resultados refuerzan la intervención de la variable tiempo como un factor explicativo en las asociaciones anteriores, toda vez que las situaciones de hacinamiento o allegamiento ocurren, la mayor parte de la veces, en períodos de tiempo intermedios o avanzados en la evolución de un hábitat. 


\section{Influencia de las Características Físicas del conjunto}

En relación a este tipo de características destaca la relación verificada entre la topografía del terreno, el índice de infraestructura (.36*) y el Índice de Problemas Físicos registrados en el conjunto $\left(.-19^{* *}\right)$. Las correlaciones indican que en los asentamientos construidos en terrenos con pendientes pronunciadas, se evalúa mejor la infraestructura, al mismo tiempo que la población manifiesta una menor presencia de problemas como basurales cercanos, alcantarillas tapadas o inundaciones. Estos datos son coincidentes con la calidad y cantidad efectiva de la infraestructura en conjuntos residenciales ubicados en cerros o terrenos con fuertes pendientes, ya que en ellos el Estado ha debido efectuar una mayor inversión en este tipo de dotaciones, en la medida que el Programa de Lotes en Servicios más que una solución a un problema de vivienda, constituye una acción de saneamiento y urbanización, lo cual es claramente percibido por los habitantes.

La topografía resultó significativamente asociada además con los problemas sociales percibidos en el conjunto $\left(-.33^{* *}\right)$, la participación comunitaria $\left(.18^{* *}\right)$, la forma como se organiza la población para efectuar actividades de mejoramiento $\left(.22^{* *}\right)$ y el índice de organizaciones existentes (.-.22**). Nuevamente en los conjuntos con pendientes pronunciadas o fuertes se presenta una situación más favorable, toda vez que en esos casos la población denuncia menos problemas sociales, registrando un nivel más elevado de participación. Cuando la población realiza alguna actividad, predomina una organización que tiende a involucrar a toda la población en vez de sectorizarse por calles o manzanas, como ocurre en los conjuntos sin pendiente.

Por último se registraron un conjunto de relaciones con la variable referida a la estructura espacial del conjunto que caracteriza la diferenciación de vías en la trama urbana. A mayor jerarquización de vías se perciben menos problemas físicos $\left(.-12^{*}\right)$ a la vez que se evalúa de mejor forma la infraestructura existente (.48**), y las personas señalan que cuando efectúan acciones conjuntas, la organización predominante incluye a todos los habitantes de la población $(.23 *$ ). Estos resultados reafirman la hipótesis que una estructura espacial legible para el habitante, derivada de una jerarquización clara de sus vías, favorece el dominio territorial.

\section{CONCLUSIONES}

El análisis asociativo efectuado permitió establecer un conjunto de relaciones entre dimensiones sociales y fisicoespaciales relativas a los procesos de desarrollo progresivo a nivel de los tres sistemas considerados en la investigación.

El examen de las correlaciones obtenidas revela la presencia de factores que, por su fuerza y consistencia, permitieron interpretar y estructurar las relaciones encontradas. Tal es el caso de las variables temporales que proporcionaron no sólo una caracterización de las variaciones del fenómeno de la progresividad, sino también posibilitaron integrar asociaciones aisladas de difícil interpretación.

En el sistema familia-vivienda el tiempo de residencia influye decisivamente en la secuencia de diversas dimensiones del desarrollo progresivo. Si bien se manifiesta de manera irregular y con una fuerte concentración de intervenciones en la caseta y en la casa durante etapas iniciales, tiende después a un notorio estancamiento de la progresividad atribuible a la instalación de la unidad sanitaria. Lo mismo ocurre con los arreglos al 
sitio, lo cual indica que el desarrollo progresivo da cuenta de una dinámica de lugarización global que establece prioridades en las intervenciones que trascienden la búsqueda de una habitabilidad mínima representada por la construcción de recinto para dormir y estar.

Esto resulta especialmente claro en los casos de erradicación donde la necesidad de lugarización constituye una estructura de selecciones que se organiza con la emergencia misma del sistema familiar y se activa en el momento en que se ocupa un nuevo sitio, transformándolo mediante un proceso de construcción de significados asociados a dicho espacio, en lugar familiar, lo que se expresa en huellas físicas como antejardines, pérgolas y parrones, mencionados por los encuestados y constatados en terreno. En cambio, la presencia de muros medianeros o la construcción del cierro del sitio hacia la calle, aunque podrían dar cuenta de comunicaciones vinculadas a diferenciaciones de estatus de la familia respecto del vecindario, parecen ser manifestaciones de un sentido de territorialidad y resguardo, dada la prontitud relativa con que se construyen. Refuerza este análisis la influencia negativa que ejercen los problemas sociales percibidos en la valorización de los encuestados sobre la caseta sanitaria.

Por otra parte el paso del tiempo influye en el carácter definitivo que se le atribuye a la mayor parte de las piezas de la casa, aun cuando se registra un menor involucramiento de la familia en los arreglos. Esto último indica que con los años y la disponibilidad de mayores recursos, las familias recurren a la contratación de maestros para efectuar arreglos mayores que permiten contar con recintos consolidados, muchos de ellos construidos de material sólido, que requieren por tanto de mano de obra especializada.

Esta interpretación queda ratificada además por las asociaciones registradas por la variable edad de la entrevistada.

Se comprobó también que el nivel de escolaridad es un factor dinamizador del desarrollo progresivo de la vivienda y el sitio. Desde el punto de vista de los sistemas sociales autorreferentes, la interpretación de esta relación incorpora nuevos elementos al análisis al considerar la educación como potenciadora de la capacidad del sistema familiar para efectuar diferenciaciones en su entorno. La apertura a nuevos contenidos temáticos ayuda a entender por qué la educación gatilla deseos de progresar, no sólo porque ella misma involucra la idea de progreso, sino también por su capacidad para aumentar las posibilidades de selección. Así familias que comparten las pautas normativas de la subcultura de la pobreza, marcada por el fatalismo y la autocompasión, pueden abrirse a otros modelos de sentido.

En cuanto a las características de la familia fue la jefatura del hogar la que mostró mayor consistencia para dar cuenta de las variaciones en la valoración de los atributos y recintos de la caseta sanitaria y en relación al involucramiento de la familia en los arreglos. Una familia donde el padre ejerce la jefatura del hogar resulta más favorable para la progresividad habitacional, mientras que cuando ese rol es ejercido por otra persona el efecto positivo disminuye significativamente.

A su vez el tamaño de la familia constituye otro factor que ejerce influencia sobre el desarrollo progresivo del sitio, lo que resulta especialmente útil para clarificar la función de los allegados en el proceso. Ellos tienden a participar en este tipo de arreglos porque constituye, en cierta medida, un espacio común, como es el patio o los espacios de tránsito entre la propia casa y la calle, no verificándose esta participación respecto a la vivienda principal, significada como lugar privado, siendo por tanto responsabilidad de la familia que allí habita llevar a cabo la progresividad. Este resultado plantea además importantes 
implicaciones para el análisis de la dinámica sociofísica del allegamiento, en especial para el establecimiento de límites en la lugarización y la fijación de fronteras de sentido que identifica como sistema a cada familia al interior de un mismo sitio.

Por otra parte, los arreglos decididos por toda la familia implican mayores niveles de desarrollo progresivo de la vivienda. Estos rasgos ponen de manifiesto que sobre el sistema familiar se producen procesos de reforzamiento del sentido ya que cuando todos sus miembros participan, se genera un mayor dinamismo que si cada uno actúa por separado y si las decisiones son tomadas únicamente por el jefe del hogar.

Pero no sólo la dinámica interna del sistema familiar afecta la característica que asume la progresión, pues los datos obtenidos permitieron observar que determinados rasgos externos también pueden provocar situaciones de resonancia. La presencia de un menor grado de sociabilidad entre vecinos y la percepción de problemas sociales en los conjuntos se asocian a una menor evaluación de ta caseta. Tal resultado confirma otros encontrados en diversas investigaciones que han concluido que la percepción de delincuencia constituye la mejor predicción para la satisfacción residencial y vecinal (Lee, B., 1986), así como la percepción de condiciones de inseguridad influye negativamente en la valoración de las soluciones habitacionales inhibiendo la sociabilidad vecinal, la configuración de comunidades y la participación comunitaria (De la Puente, P.; Muñoz, P.; Torres, E., 1990).

En el sistema vecinal las variables tiempo de residencia en la población y edad de la encuestada también permitieron aclarar y ordenar un gran número de asociaciones significativas.

El transcurso del tiempo, en este caso, implica una disminución de los rasgos típicamente vecinales, de manera que aspectos tales como la sociabilidad son más fuertes entre las beneficiarias recién llegadas que entre las antiguas. Esta desarticulación de los vecindarios a medida que pasan los años en los contextos sociales estudiados, constituye un hallazgo sorprendente que abre una interesante área de estudio para futuras investigaciones. Al parecer la fuerte necesidad de arraigo que induce a los nuevos residentes a incrementar su sociabilidad no logra mantenerse a través del tiempo, siendo insuficiente para sobrellevar los estímulos negativos provenientes de otros sistemas, tendiendo a replegarse hacia la familia.

El número de personas que habitan el sitio constituye una característica del sistema familiar que se vincula con los arreglos efectuados en el espacio intermedio. Lo anterior implica que estos espacios semipúblicos experimentan una suerte de privatización o apropiación por parte de personas que posiblemente ni siquiera forman parte del sistema familiar, como es el caso de los allegados. En otros términos, carecer de un espacio privado o tenerlo de manera muy precaria haría que se volcara la atención hacia el entorno espacial inmediato a las viviendas, haciendo arreglos en un espacio público cercano en conjunto con otros vecinos.

Otro efecto que puede ser asumido como resonancia en este nivel es la relación encontrada entre la sociabilidad vecinal y la participación comunitaria, la que muestra fuertes vínculos entre la estructura vecinal y la acción participativa de los habitantes en arreglos colectivos al espacio intermedio, de modo que el incremento en la sociabilidad refuerza la participación y viceversa.

En relación a la influencia de las variables fisicoespaciales se observó que la calidad de la infraestructura repercute positivamente en la sociabilidad vecinal. Por otra parte, la presencia de pendientes en la topografía del terreno, una estructura jerarquizada de vías 
y tamaños pequeños de los conjuntos residenciales son factores que afectan las características del vecindario, planteando interesantes y novedosas relaciones hasta ahora muy poco estudiadas.

Las correlaciones efectuadas con las variables que caracterizaron diversas dimensiones del sistema comunidad presentan un comportamiento similar a los otros dos sistemas analizados.

Así el mayor tiempo de residencia y la edad implican mayor percepción de problemas sociales y de organizaciones comunitarias, lo cual resulta altamente consistente con el resto de indicadores que evaluaron estos factores. La percepción de problemas y de este tipo de organizaciones involucra una exposición a contenidos temáticos propios de la acción colectiva de mejoramiento, con lo cual resulta comprensible que se manifiesten opiniones más críticas entre los residentes antiguos, que han internalizado muchas demandas de estas organizaciones pese a no participar activamente en ellas; mientras que los recién llegados se encuentran mucho más volcados hacia la comunicación familiar, en gran medida ajenos a lo que ocurre en su entorno.

Por otra parte el número de personas y de casas por sitio se encuentran asociadas, aunque débilmente con las opiniones sobre los problemas sociales y la infraestructura física del conjunto. También demostraron tener baja influencia sobre las dismensiones de la comunidad aspectos fisicoespaciales, como la construcción aislada o pareada de las casetas y su adosamiento a la casa.

En cambio otras variables arquitecturales juegan un rol clarificador en las variaciones que registran los datos en este sistema. Es así como la topografía del terreno donde se emplaza el conjunto residencial ejerce influencia sobre la percepción de problemas, los niveles de participación, las formas en que se organiza la comunidad para efectuar arreglos y el número de organizaciones existentes. Esta tendencia da cuenta de niveles de una integración social elevada relacionada con una mayor visibilidad que adquiere el entorno en situaciones de pendiente. Aquí el conjunto residencial puede ser aprehendido como un todo con mayor facilidad, perdiendo importancia la cuadra o el pasaje como delimitaciones típicas del plano. La identificación más fuerte pasa a ser entonces "el cerro" como criterio diferenciador respecto del ambiente externo y que une a las familias que habitan ese espacio.

Por último destacan en este sistema la importancia que adquiere la jerarquización de las vías sobre la evaluación de los problemas físicos, la dotación y calidad de la infraestructura existente y la forma de organización de los habitantes cuando efectúan arreglos en el espacio intermedio. Todo esto refuerza la idea que una jerarquización de calle que logra separar ámbitos públicos mediante vías principales, de espacios semipúblicos al interior de pasajes, no sólo favorece una mejor evaluación de la infraestructura y minimiza los problemas físicos, sino que también contribuye a organizaciones sociales que integren a los habitantes de todo un conjunto habitacional, evitando la atomización y el debilitamiento de la participación comunitaria.

\section{CONSIDERACIONES TEÓRICAS A LA LUZ DE LOS RESULTADOS}

La información recopilada en la presente investigación permite efectuar una serie de precisiones al marco de referencia utilizado, haciendo explícitas algunas relaciones que 
se habían presentado de manera genérica en la etapa de elaboración teórica. Por otra parte, la incorporación de variables incluidas en las técnicas de recopilación de datos utilizadas y que no habían sido consideradas en la aplicación de la teoría de los sistemas autorreferentes y lugar al fenómeno de la progresividad habitacional han proporcionado nuevas fuentes inspiradoras de relaciones e hipótesis susceptibles de comprobar a través futuras investigaciones sobre el tema.

De todas las variables independientes consideradas para observar su comportamiento respecto de las diversas dimensiones de la progresividad habitacional, es sin duda el tiempo de residencia y la antigüedad de la población los que dan cuenta en mejor forma de la progresión tanto en la familia como en el vecindario y la comunidad.

A nivel del primer sistema, el factor temporal adquiere un carácter articulador de la acción interna sobre el sitio y la vivienda, pero también produce efectos decisivos sobre las posibilidades de apertura de la comunicación familiar hacia el sentido vecinal y comunitario.

Los datos mostraron consistentemente que a mayor tiempo en una población se registraba una menor progresividad de la vivienda y del sitio atribuible a la instalación de la unidad sanitaria, así como disminuía el involucramiento de la familia en los arreglos. Estos resultados son de gran importancia para comprender la progresividad no como un proceso lineal de aumento relativamente sostenido y sumatorio, sino como una función que posee un impulso inicial fuerte, que perdura dos o tres años, perdiendo con posterioridad influencia en la completación de la vivienda. Lo anterior ocurre porque el proceso de lugarización en ese lapso es menos imperioso que al inicio del programa cuando todo resulta extraño y la ansiedad de apropiación del nuevo espacio es aplacada por las numerosas intervenciones a la caseta, la vivienda y el sitio. Esta caracterización es más atingente a las situaciones de erradicación donde la instalación de las unidades sanitarias adquiere una función prioritaria de tipo habitacional a diferencia de la radicación donde el programa cumple con su rol de saneamiento. En este último caso no es posible postular un estancamiento de la progresividad habitacional, pues en ellas el desarrollo de la vivienda ya ocurrió siendo el impacto de la unidad sanitaria sobre la progresividad mínimo. Para decirlo de otra forma, en las erradicaciones la unidad sanitaria entregada es evaluada con referencia a cuánto falta para completar la vivienda, mientras que en las radicaciones se percibe con el optimismo propio de quien culmina un proceso.

Los resultados obtenidos sugieren que la progresión habitacional es producto de factores que incluyen efectos de comunicación que exceden el sentido familiar, aunque es éste el que posee mayor peso interpretativo. Las peculiaridades que asume la sociabilidad vecinal fue una de las dimensiones que en forma más nítida reflejó conexiones con aspectos relativos a la dinámica de la progresividad, apoyando la presencia de fenómenos de la resonancia postulados en el marco teórico del estudio, esto es que estimulaciones experimentadas por el sistema familiar, derivadas de cambios ocurridos en el entorno (vecindario), son capaces de promover nuevos estados en él.

Por otra parte la influencia que las variables temporales demostraron tener sobre el comportamiento del sistema familiar y su relación con el entorno vecinal y comunitario, obligan a un análisis más detenido del fenómeno de apertura y clausura del sistema, cuestión que fue escasamente abordada en el marco teórico. Una distinción que ayuda a una mejor interpretación de los datos es el hecho que aparecen diversos tipos de clausura de acuerdo al tiempo de residencia o, en otras palabras, a la experiencia acumulada del entorno. 
Existe un primer tipo de clausura comunicativa (cerrada) sin consideración del entorno vecinal, representada por las familias recién llegadas a una población que tienen como primera prioridad la conformación de su propio lugar, lo que es típico de situaciones de erradicación inicial. En este caso la clausura es producto del exceso de complejidad interna derivada del déficit de habitabilidad que enfrenta una familia al no contar con una vivienda y un sitio mínimamente confortable. Ella no percibe el entorno sociofísico externo a la propia vivienda y el sitio, o lo hace de manera muy difusa, de modo que sus miembros no forman parte del vecindario o la comunidad por un rechazo a ciertas características de él, sino porque la mayor parte de la atención se encuentra volcada a concretar la lugarización del espacio privado.

Un tipo diferente de clausura comunicativa (abierta) es la ejecutada por las familias con mayor tiempo de residencia, caracterizada por un repliegue producido después de haber formado parte del vecindario o la comunidad. Efectivamente los datos indican que en una etapa intermedia, que suele ser reciente en la conformación del hábitat residencial, existen vecindarios constituidos espacialmente al interior de los límites de una cuadra que se desarticulan con el paso del tiempo. Dicho repliegue hacia la comunicación familiar no es absoluto, pues se mantiene la atención sobre el entorno vecinal y comunitario. $\mathrm{Al}$ respecto muchas encuestadas, después de tomar parte en acciones comunitarias, declararon paradojalmente no pertenecer a las juntas vecinales aunque asistieran a reuniones. Lo mismo ocurrió con el conocimiento demostrado respecto de las características del vecindario pese a que no se interactuara en él. En otras palabras el vecindario no es indiferente para las personas con cierta antigüedad en el conjunto residencial, especialmente si en algún momento se interactuó en forma frecuente con vecinos.

Otra consecuencia teórica que se desprende de los resultados del estudio es que el proceso de lugarización externo a la familia asume a lo menos dos formas. Por una parte, fue posible reconocer una modalidad de apropiación del espacio intermedio significado como escenario para la realización de actividades colectivas tales como fiestas y celebraciones, sean éstas privadas - como cumpleaños-o públicas — como navidades o aniversarios patrios - donde el sentido simbólico es externo al espacio, constatándose por lo general intervenciones meramente transitorias y ocasionales. Por otra parte, se constató una lugarización donde el espacio inmediato se convierte en protagonista de la acción colectiva en la medida que es intervenido para hacerlo más grato y placentero, con lo cual el sentido comunicativo recae sobre el espacio mismo, generando huellas físicas que a su vez adquieren valor de mensaje tanto para los habitantes como para los observadores externos. Futuras investigaciones podrán descubrir si ciertas formas de ocupación del espacio presentan diversos efectos sobre el sentido vecinal o comunitario, o se basan en delimitaciones socio-físicas distintas, que incluyen a ciertos participantes o excluyen a otros, según sea el tipo de actividad a efectuar.

Las variables físico-espaciales se comportaron como factores intervinientes en el proceso e interpretables conceptualmente como irritaciones, demostrando una fuerte influencia para alterar las relaciones entre las variables sociales. Esas influencias no constituyen comunicación entre sistemas, representan en cambio exigencias estridentes ante las cuales los sistemas reaccionan de algún modo para adaptarse. Los datos tienden a confirmar esta interpretación en la medida que la relación verificada no implicaba una conciencia clara de los habitantes sobre los efectos de los factores físicos en los procesos sociales. Así, por ejemplo, se constató que la dotación y la calidad de la infraestructura física presente al interior de los conjuntos residenciales es capaz de afectar la sociabilidad 
vecinal, ocurriendo algo similar con el pareo de las casas y casetas, la topografía del terreno donde se emplaza la población, la jerarquización de vías y el tamaño del conjunto.

Es necesario señalar que estas variables representan factores de orden distinto desde el punto de vista del control, cuestión fundamental a la hora de diseñar políticas públicas. Es claro sin embargo, el carácter facilitador de dinámicas sociales integrativas que pueden asumir la presencia de áreas verdes, canchas deportivas, sedes comunitarias o una adecuada conformación del espacio a través de una estructuración vial delimitadora de espacios públicos y semi públicos. La forma en que deban introducirse esos cambios de manera que maximicen su efecto potenciador de vecindarios y comunidades constituye un tema por investigar, ya que la idea de la incorporación participativa de la población es un logro difícilmente alcanzable en situaciones de escasa acción colectiva. De hecho, por ejemplo, la casi totalidad de los mejoramientos observados en el espacio intermedio, que por su envergadura sugieren a un observador externo que en su construcción habían intervenido muchas personas, fueron en realidad el producto de la acción de familias que en forma separada extendían la lugarización más allá de su propio sitio.

Pese a lo anterior la información recolectada reafirmó las características del fenómeno de interpenetración entre el sistema vecinal y el comunitario, es decir la estructura comunicativa del vecindario centrada en la simpatía y confianza mutua, ofrece un ambiente favorable para el desarrollo de la acción comunitaria que prioriza la organización orientada a arreglos y mejoramientos. Se comprobó además que la mayor participación en organizaciones territoriales estaba significativamente asociada con la convivencia vecinal en la misma calle o pasaje.

Si se añade el hecho que la organización predominante de la acción comunitaria se articulaba por cuadra más que por manzanas o a nivel de todo el conjunto residencial y que el motivo principal para efectuar los arreglos consistía en la amistad entre los vecinos, se puede concluir que los límites socioespaciales del vecindario condicionan las fronteras de la comunidad. Este hallazgo posee importantes repercusiones teóricas pues la comunidad es un sistema distinto al vecindario, al menos en su contenido predominante que es el mejoramiento de los espacio públicos mediante la participación, sería improbable que este proceso surgiera sin la conformación previa de redes vecinales de comunicación. Por otra parte, si el límite social comunitario no excede al vecinal, cabría esperar dificultades serias para la incorporación de principios instrumentales como la división de tareas, atribución de responsabilidades, control de obligaciones entre otras herramientas que incrementen la eficiencia comunitaria y haga posible plantear y concretar acciones de mayor envergadura y que requieren incluso de la concurrencia de otras instancias sociales. Dicho de otra manera, la acción comunitaria en los casos observados parece dar cuenta de una extensión del sentido vecinal que si bien ayuda a la ejecución de arreglos le otorgan un techo muy bajo, una discontinuidad en la acción y pocas posibilidades de conexión con el entorno, puesto que no es clara la existencia de una estructura distinta al vecindario que refuerce una racionalidad orientada al logro de objetivos que supere la pura simpatía recíproca.

Las consecuencias prácticas de este hecho son múltiples. Sólo por nombrar una referida a la expresión de la comunidad y su relación con el gobierno local, cabría indicar que en las poblaciones producto de programas de saneamiento como las estudiadas prevalece una tendencia hiperatomizada de participación. Son evidentes las enormes dificultades que conlleva articular disímiles expresiones comunitarias cuando las necesidades trascienden los intereses de un grupo reducido y están referida a diversas obras de 
infraestructura al servicio de todos los habitantes de una población. A esto se suma la opinión negativa prevaleciente respecto de la labor que cumplen las juntas de vecinos, que representan el vínculo formal de la comunidad residencial con la municipalidad respectiva, con lo cual el logro de consensos colectivos para la expresión de demandas y su necesaria colaboración se hace más difícil aún.

En síntesis los datos muestran que la progresividad experimenta una evolución irregular reveladora de una asincronía en los tres sistemas estudiados. En el caso del sistema familiar ella se expresa fundamentalmente en el estancamiento que presenta el desarrollo progresivo en etapas intermedias y avanzadas en la evolución del hábitat. El vecindario ostenta una doble dinámica; por una parte muestra una involución dada la desarticulación que experimentan las redes de comunicación a medida que transcurre el tiempo, pero a la vez expresa rasgos de latencia, la cual constituye una disponibilidad potencial del sistema para futuras comunicaciones vecinales en cuanto las familias se cierran sobre sí mismas sin perder por ello su atención sobre el entorno. Por último la comunidad constituye un sistema que no ha logrado crear una estructura totalmente diferenciada del vecindario y que da cuenta de una limitada capacidad de acción colectiva.

Lo anterior no significa que a los residentes de los conjuntos estudiados les sea indiferente el mejoramiento de sus condiciones de vida y no demuestren interés por emprender acciones colectivas en este sentido. Por el contrario, los datos sugieren que los sistemas sociales identificados permanentemente mantienen la atención sobre los espacios que con distintas dinámicas y ritmos lugarizan y apropian a través del tiempo, pero que enfrentan dificultades de diverso tipo para concretar y efectuar el desarrollo progresivo de las viviendas y el entorno habitacional en forma constante y efectiva. Surge para los estudiosos, el desafío de elaborar esquemas compatibles y cada vez más afinados que permitan comprender la complejidad de un fenómeno dinámico, que ocurre simultáneamente en diversos niveles de la vida social y que exige de las instancias públicas y de los encargados de atender las demandas sociales insatisfechas, su canalización mediante mecanismos flexibles, complementarios y potenciadores de la sinergia latente en las familias, los vecindarios y las comunidades residenciales.

\section{REFERENCIAS BIBLIOGRÁFICAS}

ARnold. M.: Teorias de sistemas, mevos paradigmas: Enfoque de Niklas Luhmann, Contribuciones $\mathrm{N}^{\circ}$ 56, FLACSO; Santiago, Chile, 1988.

BallLy, A.: La organización urbana: Teorias y modelos, Ed. Nuevo Urbanismo, Madrid. 1978.

CANTER. D.: The psychology of place. Editorial The Arquitectural Press. London. 1977.

De la Puente, P.: Torres, E; Mu,ĩoz, P.: Satisfacción residencial en soluciones habitacionales de radicación y emadicación para sectores pobres de Santiago. Revista EURE ${ }^{\circ}$ 49, Santiago, Chile, 1990.

Frampton, K.: Lugar, forma e identidad: Hacia una temia del regionalismo critico. En: Toca, A. (Editor). Nueva Arquitectura en América Latina: Presente y Futuro. Editorial G. Gili, México, 1990.

García, A.: ¿Espacio masculino, espacio femenino.' En Seminario: Uso del Espacio en la Vivienda Cotidiana. Universidad Autónoma de Madrid. España, 1986.

HaRamoto, E.; SePulveda, R.: Imagen, calidad y evollición en el entorno de la vivienda social. D.T. CEDVI-FAVA. Universidad Central, Santiago, Chile, 1990.

IzUzQciza, I.: Sociedad y sistema: La ambición de la teoría. En N. Luhmann Editorial Paidós Barcelona, España, 1990.

LAQU1ÁN. A.: Vivienda básica. Políticas sobre lotes urbanos, senicios y vivienda en los países en desarrollo. C.I.ID Otawa, 1985.

LEE, M.: Islamabad: The intage, Ekistics, Vo. 25. N 150, 1968. 


\section{REVISTA DE SOCIOLOGÍA}

Llhmann, N.: Sistemas sociales: Lineamientos para una teoria general. Editorial Alianza, México, 1991.

LlHma.n. N.: Seciedad y sistema: La ambición de la teoría. Editorial Paidos, Barcelona, España, 1990.

Llhmanv, N.: Mérodo funcional y teoría de sistemas, En: "Ilustración sociológica y otros ensayos". Sur, Buenos Aires, 1973.

MUNTAÑol.A, J.: La arquitectura como lugar. Aspectos preliminares de una epistemologia de la Arquitectura. Editorial

G. Gili, Barcelona, España, 1973

Muntañola, J.: Topogénesis dos: Ensayo sobre la naturaleza social del lugar. Editorial Oikos-Tau, Barcelona, España, 1979 .

NorberG-SChUi.tz, Ch.: Arquitectura Occidental. Editorial G. Gili. Barcelona. España, 1983.

Rodríglez, D.; ARNold, M.: Sociedad y teoria de sistemas. Editorial Universitaria, Santiago, Chile, 1991.

Rosemblith, G.: La vivienda en América Latina: Una visión de la extrema pobreza. Doe. CEpaL/LPES. Santiago, 1979.

Seputiveda, O.; CaRRAsco. G.: Sectorización habitacional del verritorio y vivienda regionalizada. Doc. INVI-FAu, Universidad de Chile, Santiago, 1991.

Simmel. G.: Sociologia, Ed. Espasa-Calpe, Buenos Aires, 1939. 